특집 가공과 진동

\title{
$\mathrm{B}$ 축 회전 기능을 갖춘 복합공구대 구조물의 정/동적 안정성에 관한 연구
}

\author{
강승희 *, 김재실 ${ }^{\#}$ \\ (* 창원대학교 대학원 기계공학전공, \# 창원대학교 기계공학부)
}

\section{A Study on the Static/Dynamic Stability for the Structure of a Mill Turret with a B-Axis Tilting Facility}

\author{
Seung-Hee Kang*, Chae-Sil Kim ${ }^{\#}$ \\ (Received 10 February 2014; received in revised form 17 February 2014; accepted 24 February 2014)
}

\begin{abstract}
Techniques of tool posts are developing such that variable machining is possible using only one machine for the complication of a product's shape and to reducethe machining time. In order to develop a mill turret with a variable machining function with the mounting of mill turret units on a B-axis tilting table, we determine the static/dynamic stability ofthe structure of the mill turret. To this end, a static structural analysis and a modal analysis wereconducted. From the results of the static structural analysis, the maximum stress was found to be less than the allowable stress. By the comparing the results of the modal analysis ofthe excitation frequencies ofthe mill turret, there wereno resonance regions found. Therefore, the mill turret with theB-axis tilting facility is shown to have good structural integrity.
\end{abstract}

Key Words : Rotary Table(회전테이블), Mill Turret(복합공구대), Static/Dynamic Stability(정/동적 안정성)

\section{1. 서 론}

일반적인 $\mathrm{CNC}$ 선반용 공구대 기술은 현재 피삭 재의 회전운동, 절삭공구에 의한 원형가공형태에

\footnotetext{
* Dept. of Mechanical Eng., Graduated School of Changwon National UNIV.

\# Corresponding Author :

Dept. of Mechanical Eng., Changwon National UNIV.

E-mail : kimcs@changwon.ac.kr
}

이어 밀링기능을 수행할 수 있는 수준으로 발전해 왔다. 복합공구대(Mill Turret Unit)는 밀링 기능을 가진 공구대를 말한다. 점차 제품의 형상이 복잡해 지고 가공시간을 단축하기 위해 하나의 장비로 다 양한 가공이 가능하도록 공구대 기술은 발전되고 있다. 최근에는 회전테이블 부가형 복합공구대를 장착한 기종개발이 점차 확대되고 있는 추세이다. 지금까지 복합공구대에 대한 다양한 연구들이 진 행되어 왔다. 인덱싱 테이블의 추세에 관한 연구 ${ }^{[1]}$ 
와 복합공구대의 비틀림계 진동에 대한 연구 ${ }^{[2]}$, 회 전테이블의 구조 안전성에 관한 연구 ${ }^{[3]}$, 절삭력과 임계 돌출거리에 관한 연구누, 틸팅 인덱스 테이블 의 회전 정밀도에 관한 연구 ${ }^{[5]}$ 등이 수행되었다. 한편으로 공작기계용 $40,000 \mathrm{rpm}$ 고속주축에 대한 정/동적 해석 ${ }^{[6]}$ 과 고속 이송테이블과 컬럼의 정/동 적 거동해석 ${ }^{[7]}$ 및 $50,000 \mathrm{rpm}$ 급 초고속 주축계의 정 적/동적/열적 특성 해석 ${ }^{[8]}$ 이 수행되었다.

그러나 회전테이블 부가형 복합공구대 구조물의 안정성 해석에 관한 연구는 미흡한 실정이다. 따라 서 본 연구에서는 $\mathrm{B}$ 축 방향 회전테이블이 부가된 복합공구대를 탑재하여 다양한 가공기능을 가지는 공구대의 개발을 위해 $\mathrm{B}$ 축 회전 기능을 갖춘 복합 공구대의 구조물의 정/동적 안정성을 해석적으로 확보하고자 한다.

\section{2. 회전테이블 부가형 복합공구대의 정적 구조해석}

\section{1 회전테이블 부가형 복합공구대의 유 한요소 모델 생성}

회전테이블 부가형 복합공구대의 구동가능성 및 정·동적 구조 안정성에 대한 검증을 위하여 $3 \mathrm{D}$ 모델 링 소프트웨어인 Inventor를 이용하여 각 부품을 모 델링 하였고, Fig. 1과 같이 ANSYS Workbench에 적용하여 Fig. 2에 나타낸 유한요소모델을 생성하 였다. 이 때 적용된 요소는 Solid 187요소이고 생성 된 요소는 $1,950,087$ 개, 노드는 $3,304,802$ 개다.

\section{2 회전테이블 부가형 복합공구대의 정 적 구조해석}

회전테이블 부가형 복합공구대의 구조 건전성을 평가하기 위하여 먼저 정적 구조해석을 수행하였 다. 구조해석을 위해 하중조건과 경계조건을 Fig. 3 에 보여준 것과 같이 적용하였다. 복합공구대는 가 공 시 피삭재와 공구로부터 약 $7,000 \mathrm{~N}$ 의 힘을 받는 다. 따라서 공구가 연결될 공구 소켓의 안쪽 면에 힘을 적용하였다. 또한 회전테이블의 하부면을 완
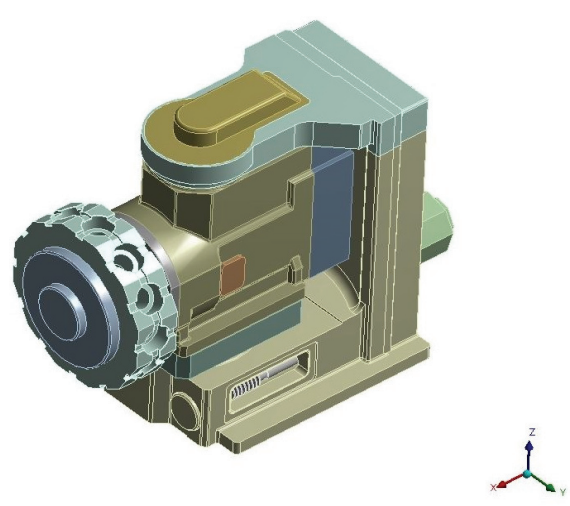

Fig. 1 An ANSYS 3D Model of Mill Turretwith a B-Axis Tilting Facility
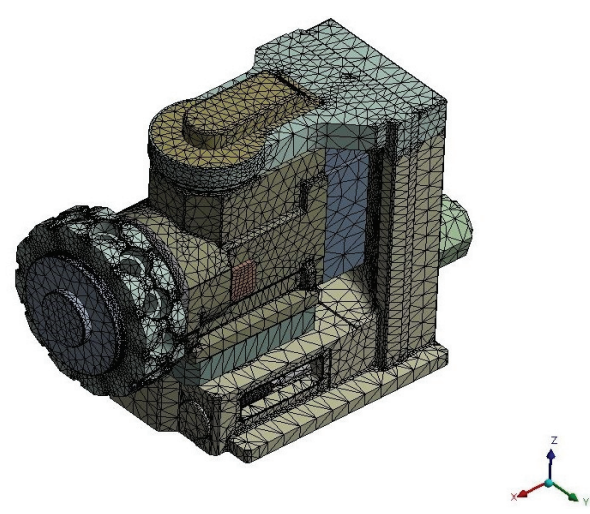

Fig. 2 A FE Model of the Mill Turret
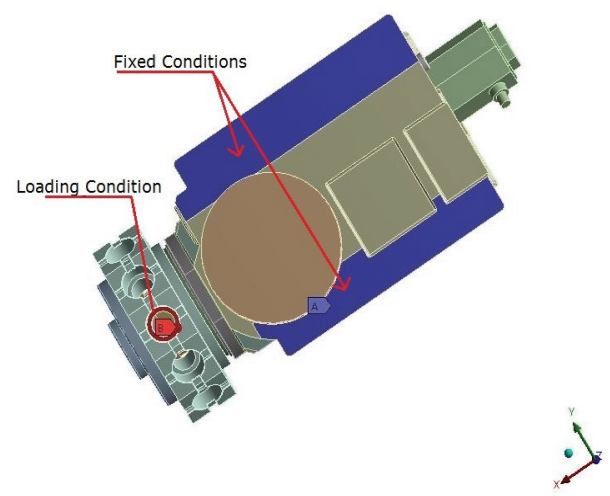

Fig. 3 Boundary Conditions of the Turning Table 
전고정 조건으로 구속하였다.

Fig. 4는 Z축 방향의 변형량에 대한 해석의 결과 로써 최대 변형량은 $6.9 \mu \mathrm{m}$ 이며 회전테이블 위에 설 치된 복합공구대에서 발생한다. 이 변형량은 매우 크기가 작아 회전테이블 부가형 복합공구대의 안 정성에 거의 영향을 미치지 않을 것으로 보인다.

다음으로 정적해석의 결과의 하나인 응력해석 결과를 Fig. 5에 나타내었다. 최대응력은 복합공구대의 공구회 전축이 연결되는 부위에서 발생한 $22.9 \mathrm{MPa}$ 으로써 복합

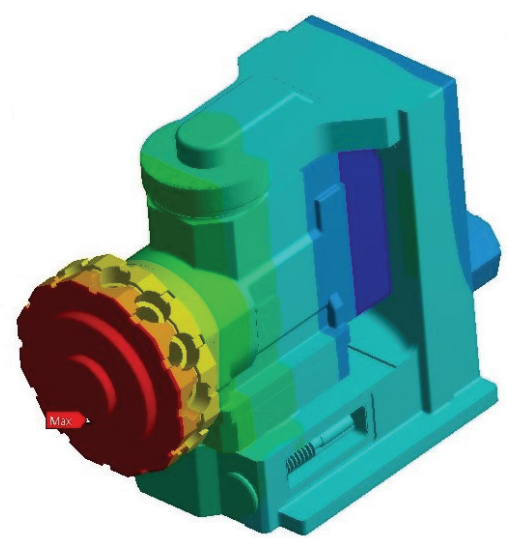

Fig. 4 Deformation Results of Static Analysis

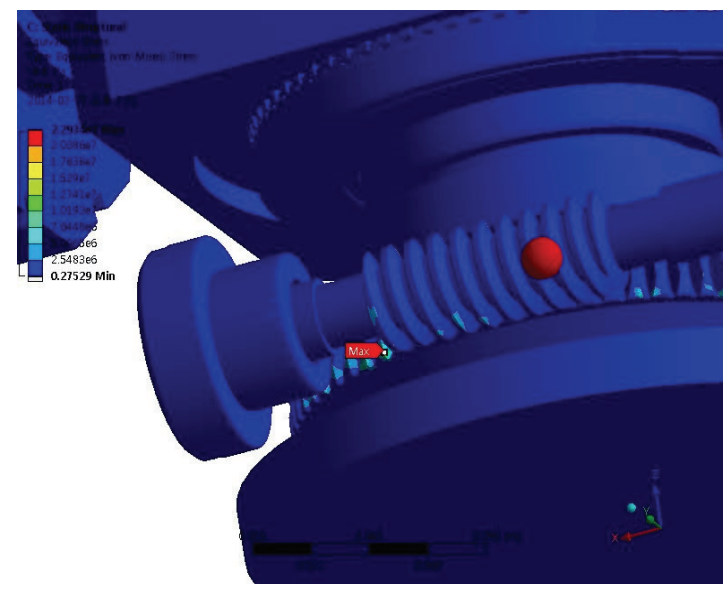

Fig. 5 Stress Results of Static Analysis
공구대의 재료인 구조용 강의 항복강도에 해당하는 $250 \mathrm{MPa}$ 보다 충분하게 작다.

\section{3. 회전테이블 부가형 복합공구대의 동적 안정성 분석}

\section{1 회전테이블 부가형 복합공구대의 가진 원 분석}

복합공구대의 가진원은 인덱싱(Indexing), 밀 드 라이빙(Mill Driving)에 사용된 기어 열에 의해 결 정되고 회전테이블의 가진원은 회전 시 사용된 기 어열에 의해 결정된다. Fig. 6에 복합공구대의 터렛 과 공구의 구동원리를 설명하기 위해 내부 모습을 나타낸 것이다. 터렛은 빌트인 모터에 연결된 스핀 들샤프트와 스핀들 풀리 및 벨트로 동력이 전달되 어 전방스플라인샤프트의 스퍼기어와 맞물려 있는 선회 커빅 커플링을 통해 터렛을 회전시킨다. 이것 을 인덱싱 기능이라고 하며 이때 빌트인 모터가 $3,000 \mathrm{rpm}$ 으로 회전하고 스핀들 풀리와 샤프트 풀리 의 직경이 각각 $8 \mathrm{~cm}$ 와 $7.7 \mathrm{~cm}$ 이므로 전/후방 스핀 들샤프트는 $1,540 \mathrm{rpm}$ 으로 회전하게 된다.

공구의 구동원리는 빌트인 모터에 연결된 스핀 들샤프트와 샤프트가 베벨기어-a와 $\mathrm{b}$ 로 연결된 드 라이브샤프트로 동력을 전달하여 공구가 회전하게

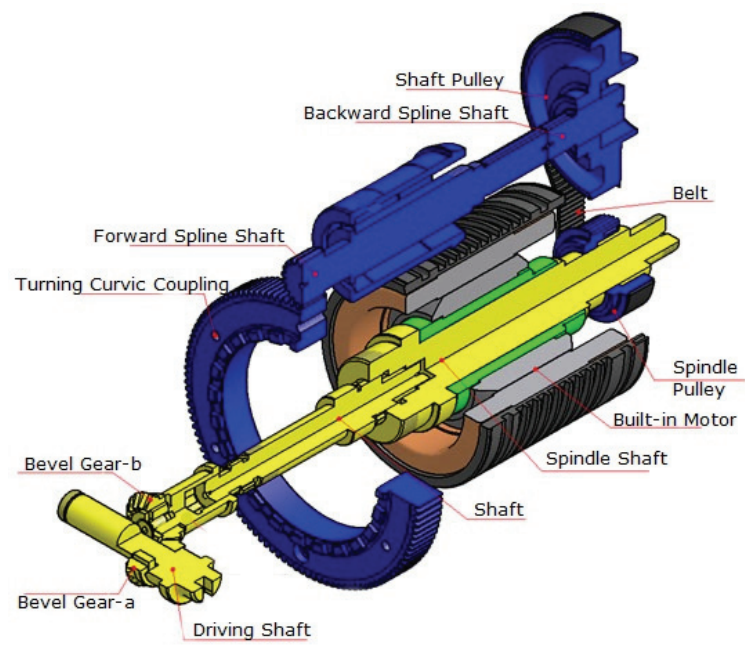

Fig. 6 Operation Principle of a Turret and Tools 


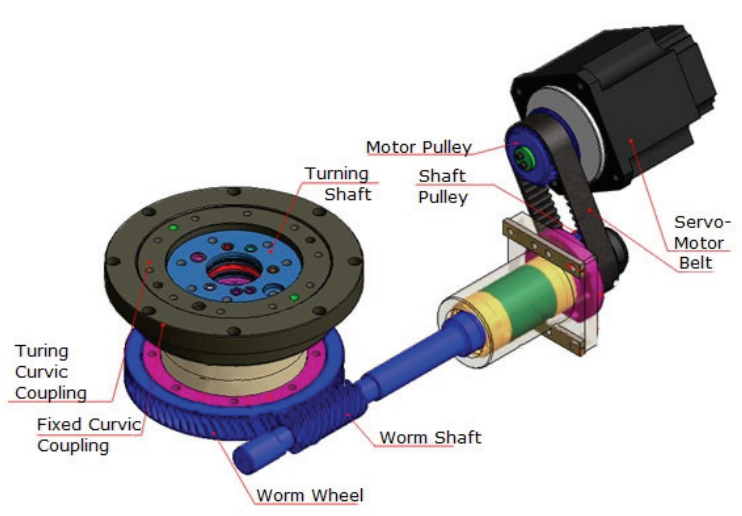

Fig. 7 Operation Principle of a Rotary Table

Table 1 The Frequency of Gear Train using Indexing Function

\begin{tabular}{c|c|c}
\hline $\begin{array}{c}\text { Shaft } \\
\text { Rotating } \\
\text { Speed }\end{array}$ & \multicolumn{2}{|c}{ Excitation Frequency for Indexing } \\
\hline \hline $1,540 \mathrm{rpm}$ & Number of Teeth (20) & $513.3 \mathrm{~Hz}$ \\
\hline
\end{tabular}

Table 2 The Frequency using Mill Function

\begin{tabular}{c|c|c}
\hline $\begin{array}{c}\text { Rotating } \\
\text { Speed }\end{array}$ & \multicolumn{2}{|c}{$\begin{array}{c}\text { Excitation Frequency for Mill } \\
\text { Driving }\end{array}$} \\
\hline \hline $5,000 \mathrm{rpm}$ & Number of Teeth (19) & $1583.33 \mathrm{~Hz}$ \\
\hline
\end{tabular}

Table 3 The Frequencies of Gear Train of Rotary Table

\begin{tabular}{c|c|c}
\hline $\begin{array}{c}\text { Table } \\
\text { Rotating } \\
\text { Speed }\end{array}$ & Excitation Frequency for Rotary Table \\
\hline \hline \multirow{2}{*}{$200 \mathrm{rpm}$} & Number of Lead (1) & $3.33 \mathrm{~Hz}$ \\
\cline { 2 - 3 } & Number of Teeth (72) & $240 \mathrm{~Hz}$ \\
\hline \multirow{2}{*}{$300 \mathrm{rpm}$} & Number of Lead (1) & $5 \mathrm{~Hz}$ \\
\cline { 2 - 3 } & Number of Teeth (72) & $360 \mathrm{~Hz}$ \\
\hline
\end{tabular}

되며 이 동작을 밀 드라이빙이라고 한다. 이 때 빌 트인 모터의 회전속도는 5,000rpm이고 베벨기어-a 와 $b$ 의 잇수는 모두 19 개로 잇수비가 1 대 1 이다.

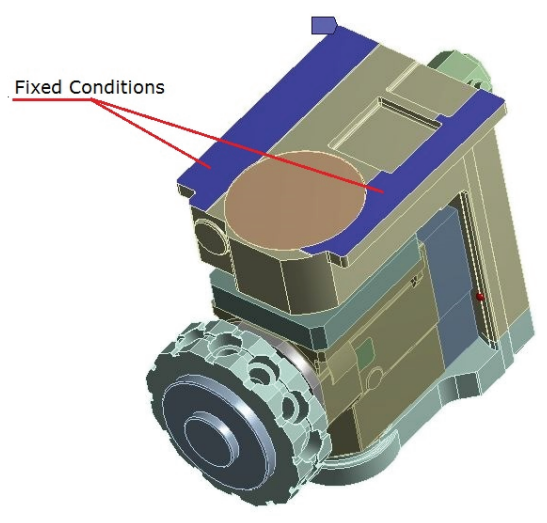

Fig. 8 Boundary Condition for Modal Analysis

Fig. 7은 회전테이블의 구동원리를 설명하기 위 한 회전테이블의 구선도이다. 회전테이블은 별도의 서보모터로 구동되며 서보모터의 풀리는 샤프트풀 리와 벨트로 연결되어 웜 샤프트에 동력을 전달하 고 웜 휠의 회전으로 테이블을 동작시킨다.

터렛의 인덱싱 수행 시, 빌트인 모터의 속도는 $3,000 \mathrm{rpm}$ 이고 밀 드라이빙의 경우는 $5,000 \mathrm{rpm}$ 이다. 그리고 회전테이블 서보모터의 속도는 200 $300 \mathrm{rpm}$ 이다. 가진 주파수의 계산과정은 각 모터의 속도와 각 기어 잇수의 곱으로 회전테이블 부가형 복합공구대의 가진 주파수를 산출하였다. 각 모터 의 속도는 각각 Table 1에서 3에 나타내었다.

\section{2 회전테이블 부가형 복합공구대의 동적 안정성 분석}

회전테이블 부가형 복합공구대의 동적 안정성을 확인하기 위해 모드 해석을 수행하여 공진영역을 확인하였다. 해석 결과와 외부에서 가해지는 가진 원인 빌트인 모터의 인덱싱, 밀 드라이빙 속도와 회전테이블 부가형 복합공구대의 각 모드별 고유 진동수가 일치하는 영역이 존재하는지를 확인하였 다. Fig. 8은 모드 해석을 위해 구속조건을 부여한 모습으로써 회전테이블 부가형 복합공구대의 하부 면을 완전고정 조건으로 구속한 모습이다. 


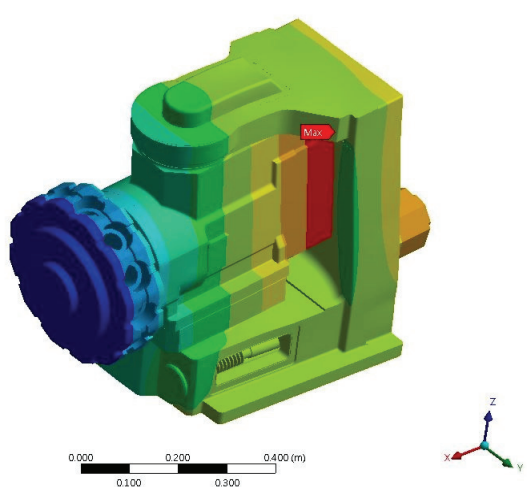

Fig. 9 First Mode Shape

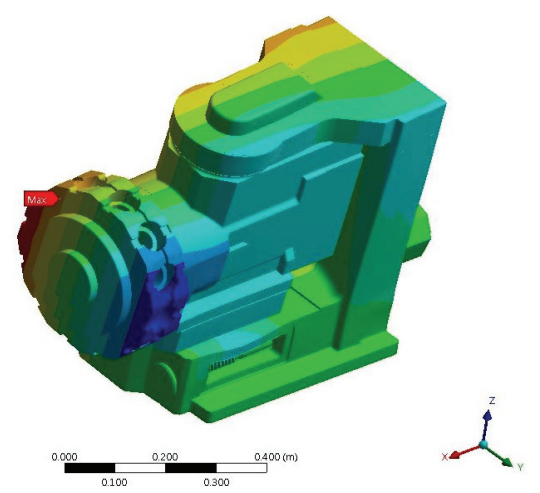

Fig. 10 Second Mode Shape

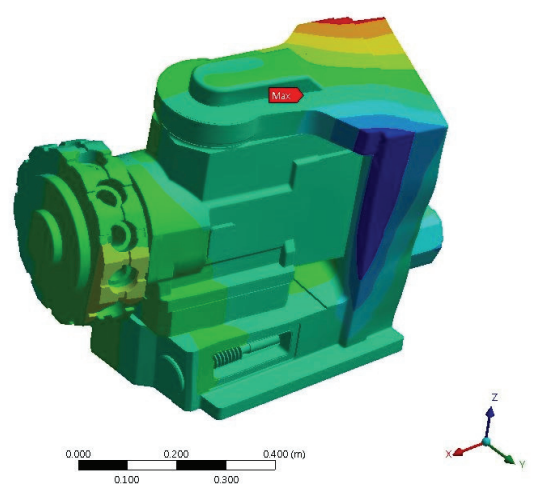

Fig. 11 Third Mode Shape

Figs. 9에서 13은 모드 해석 결과로 나타난 고유 진동수 및 모드형상을 나타내고 있으며 Table 4에 회전테이블 부가형 복합공구대의 주요 고유진동수 를 정리하였다. Tables 1 에서 3 에서 나타낸 가진 주 파수와 Table 4의 각 모드 진동수를 비교해보면 회

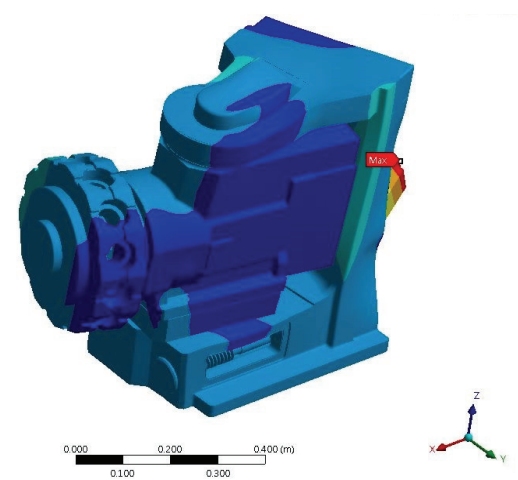

Fig. 12 Fourth Mode Shape

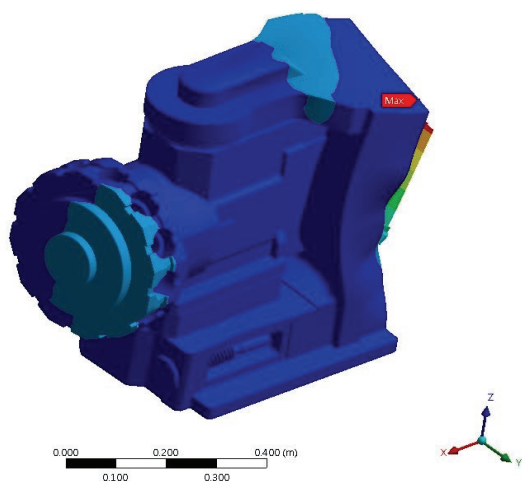

Fig. 13 Fifth Mode Shape

Table 4 The Frequencies of Each Mode

\begin{tabular}{|c|c|}
\hline Mode & Frequency \\
\hline 1 & 272.93 \\
\hline 2 & 348.74 \\
\hline 3 & 470.98 \\
\hline 4 & 691.59 \\
\hline 5 & 708.74 \\
\hline 6 & 874.83 \\
\hline
\end{tabular}

전테이블 부가형 복합공구대와 가진원 사이에 진 동수가 겹쳐 공진이 발생할 가능성이 있는 영역은 존재하지 않음을 확인하였다 


\section{5. 결론}

본 논문에서는 다양한 가공 기능을 수행할 수 있도록 고안된 $\mathrm{B}$ 축 회전테이블 부가형 복합공구대 의 정/동적 안정성을 평가하였다.

1. 정적 구조해석 결과 회전테이블 부가형 복합 공구대에서 발생하는 최대응력이 허용응력보다 충 분히 작으므로 정적 구조 안정성을 확인하였다.

2. 모드 해석을 수행한 결과로 얻은 고유진동수 와 인덱싱, 밀 드라이빙 및 테이블 회전 시 발생하 는 가진 주파수를 비교한 결과 공진의 위험이 없 으므로 동적 안정성을 확인하였다.

\section{후 기}

“이 논문은 2013 2014년도 창원대학교 연구비에 의하여 연구되었음."

\section{REFERENCES}

1. C. S. Kim, J. H. Choi, and J. U. Kim. "A Study on Design and Technique Trend of Indexing Table" Journal of KSMTE, 19(2), pp. 141-146, 2010.

2. C. S. Kim, S. T. Kim, S. Y. Cho, and H. H. Jung, "The Effect of Gear Contact Stiffnesses on the Vibration of Torsional Geared Systems for a Mill Turret" Journal of the KSMPE, 8(2), pp. 32-39, 2009.

3. C. S. Kim, J. H. Choi, and J. H. Park, "Structural Stability Analysis of the Rotary Table for a B-axis Mill Turret", Proceedings of KSMPE, pp. 145-146, 2010.5.

4. J. H. Choi, C. S. Kim, and S. Y. Cho, "A Study on the Relationship between the Cutting Force and the Critical Ejecting Distance of Disk for a Mill Turret", Journal of the KSMPE, 12(1), pp.
110-116, 2013.

5. G. S. Kim, C. M. Lee, and T. H. Lee, "A Study on the Rotational Accuracy Measurement of Tilting Index Table", Proceedings of KSMPE, pp. 47, 2011.11.

6. D. H. Kim, C. M. Choi, and H. J. Choi, "Static and Dynamic Analysis and Optimization Design of 40,000-rpm High-Speed Spindle for Machine Tools", Trans. Korean Soc. Mech. Eng. A, 37(1), pp. 105-111, 2013.

7. C. H. Lee, H. S. Lee, and ISIDA, "Static and Dynamic Behaviour Analysis for High Speed Table and Column", Proceedings of KSPE, pp.1103-1107, 1998.10.

8. S. I. Kim, J. W. Cho, W. J. Lee, and Y. H. Lee, "Static/Dynamic/Thermal Characteristics Analysis of a High-Speed Spindle System with 50,000rpm", Proceedings of KSMTE, pp. 494-499, 2003.05.

9. Singiresu S. Rao, Mechanical Vibrations, Prentice Hall, 2004.

10. J. E. Shigley, C. R. Mischke, and R. G. Budynas, Mechanical Engineering Design, McGraw-Hill, 2006.

11. TSNE, ANSYS Workbench Training Manual WB Mechanical Basic, Gyalim, 2012.

12. TSNE, ANSYS Workbench Training Manual v12.0 WB Mechanical Vibration, Gyalim, 2009.

13. J. S. Song, AUTODESK INVENTOR Advance Course, Chungdam Books, 2014. 